\title{
O FENÔMENO DA REPETIÇÃO NA PESQUISA JURÍDICA: UMA ANÁLISE CRÍTICA DA AUSÊNCIA DE INOVAÇÃO NOS TRABALHOS ACADÊMICOS DE DIREITO
}

\section{THE PHENOMENON OF REPRODUCTION IN JURIDICAL RESERCH: CRITICAL ANALYSIS OF THE LACK OF INNOVATION IN THE JURIDICAL DISSERTATIONS}

\author{
${ }^{1}$ Laura Campolina Monti \\ ${ }^{2}$ Nathalia Guedes Azevedo
}

\section{RESUMO}

O presente trabalho se propõe a investigar o conceito e a operacionalização da pesquisa em sua modalidade jurídica, buscando estabelecer pontos balizadores para tal atividade. $\mathrm{O}$ ponto central da reflexão é o papel da inovação no âmbito da pesquisa no campo do Direito. Nessa linha, o trabalho se debruça especificamente sobre o papel da pesquisa jurídica e dos debates acadêmicos, tendo como parâmetro as dissertações de mestrado produzidas nos últimos três anos pelos dissentes de três das mais relevantes instituições de ensino do estado de Minas Gerais.

Palavras-chave: Pesquisa jurídica, Inovação em direito, Pós-graduação stritu sensu, metodologia

\begin{abstract}
This research aims to investigate the concept and implementation of juridical research seeking to establish benchmarks points for such activity. The central point of reflection is the role of innovation in researches developed in the field of law. The work specifically focuses on the role of juridical research and academic debates, using as parameter the master's theses produced in the last three years by the students from three of the most important educational institutions in the state of Minas Gerais.
\end{abstract}

Keywords: Juridical research, Innovation in law, Methodology

\footnotetext{
${ }^{1}$ Mestrando em Instituições Sociais, Direito e Democracia na Universidade FUMEC, Belo Horizonte - MG (Brasil). E-mail: laura.campolinamonti@hotmail.com

${ }^{2}$ Mestrando em Instituições Sociais, Direito e Democracia na Universidade FUMEC, Belo Horizonte - MG

(Brasil). E-mail: nathalia_guedes@outlook.com
} 


\section{INTRODUÇÃO}

O debate sobre a pesquisa e o ensino jurídico no Brasil é tradicional, permanecendo sempre aceso. Tenta-se, incansavelmente, nomear os problemas e definir soluções. Nessa linha, o presente trabalho aborda inicialmente a temática da pesquisa jurídica em si, seu conceito, seus limites e seus desafios. Isso porque se entende que, seja qual for a matéria de estudo, não se poderá compreendê-la ou criticá-la com excelência sem uma significativa e fundamentada reflexão.

A confusão entre pesquisa jurídica e prática jurídica, tem alcançado um espaço cada vez mais impactante no âmbito jurídico, na medida em que "a otimização de acesso às fontes vem acompanhada da intensificação das demandas da vida moderna, exigindo cada vez mais que as respostas a serem dadas, seja na vida acadêmica ou na prática jurídica, ocorram no menor prazo de tempo possível" (KESSELRING, SALES e OLIVEIRA FILHO, 2015). Assim, a preocupação com a celeridade e o imediatismo, característico da sociedade atual, têm repercutido no âmbito acadêmico fomentando um sistema de produção em série de trabalhos supostamente científicos que, pela exigência de volume, não raro acabam por prescindir do aprofundamento necessário e da reflexão prolongada.

Para além das dificuldades inerentes à mentalidade da sociedade contemporânea, há que se considerar o fluxo crescente de exigências quantitativas relacionadas à produção cientifica no âmbito jurídico. A avaliação dos programas de pós-graduação, a pontuação dos currículos e a qualificação dos profissionais têm cada dia mais sido associada ao número de trabalhos produzidos e publicados. Enquanto, por um lado, é certo que as exigências da $\mathrm{CAPES}^{1}$, por exemplo, incentivam a produção acadêmica, impedindo que docentes e discentes se afastem da reflexão acadêmica e da produção cientifica, por outro é inegável que a exigência quantitativa tem resultado em um aumento do número de trabalhos sem nenhum conteúdo inovador.

\footnotetext{
1 ORIENTAÇÕES PARA APCN - 2016. Disponível em:

http://www.capes.gov.br/images/documentos/Criterios_apcn_2016/Criterios_APCN_Direito.pdf
} 
Em face desse quadro, a reflexão que se propõe a seguir se relaciona exatamente com o papel na inovação na pesquisa jurídica. Com raras exceções, dissertações e teses não possuem uma hipótese, mas partem de um problema e, após recensear as diferentes possibilidades de solução, indicam qual lhes parece ser a mais adequada das respostas (VERONESE e FRAGALE FILHO, 2015). O que se busca analisar é o impacto da produção em série na qualidade, bem como na utilidade, do material produzido.

A presente pesquisa foi desenvolvida a partir da análise de fontes doutrinárias, bem como do levantamento de dados acerca dos trabalhos de dissertação produzidos nos anos de 2013, 2014 e 2015 no âmbito dos programas de pós-graduação strito sensu em Direito da Universidade Federal do Estado de Minas Gerais (UFMG), da Pontifícia Universidade Católica de Minas Gerais (PUC) e da Universidade FUMEC. Os dados relativos aos programas de pós-graduação strito sensu acrescentaram ao trabalho a as evidências práticas da discussão que se pretendeu realizar.

\section{A PESQUISA JURÍDICA}

Atualmente, o entendimento de que o saber jurídico não se restringe a mera dogmática já é consenso entre a maioria dos teóricos do Direito. Até meados do século $\mathrm{XX}$, no entanto, afirmava-se que a ciência do Direito se limitava a um conjunto de teorias sobre as normas em vigor e suas exigências práticas. O Direito era compreendido apenas como um sistema regulatório, cabendo à Ciência do Direito a sistematização e interpretação desse sistema. Sendo compreendido como de natureza estritamente dogmática, o saber jurídico deveria se preocupar com questões como vigência e eficiência procedimental, sendo alheia à sua área de atuação a problematização dos fenômenos sócio jurídicos, bem como as formas de atuação dos mesmos.

A pretensa neutralidade da Ciência Jurídica é um dos principais objetivos, por exemplo, da Teoria Pura do Direito, de Hans Kelsen, que busca repousar tal neutralidade em uma postura alheia às discussões morais, políticas e relativas a valores. Em outras palavras, o objeto único do Direito seriam as normas jurídicas.

No entanto, mesmo Kelsen sabe muito bem que uma ciência reflete, em última análise, o seu método. Portanto, mais uma vez, a Teoria Pura socorre-se no positivismo científico reafirmando a necessidade de uma pureza metodológica capaz de 
delimitar com exatidão os limites de cada ramo do saber, isolando-os e levando ao extremo a segunda máxima cartesiana: dividir para melhor conhecer (FRATTARI, 2002, p.3). Deste modo, Kelsen busca valer-se do método estritamente lógico-formal para a ciência do direito, conforme se verifica em seus escritos:

\begin{abstract}
Como teoria, quer única e exclusivamente conhecer o seu próprio objeto. Procura responder a esta questão: o que é e como é o Direito? Mas já não lhe importa a questão de saber como deve ser o Direito, ou como deve ele ser feito. É ciência jurídica e não política do Direito.

Quando a si própria se designa como 'pura' teoria do Direito, isto significa que ela se propõe garantir um conhecimento apenas dirigido ao Direito e excluir deste conhecimento tudo quanto não pertença ao seu objeto, tudo quanto não se possa, rigorosamente, determinar como Direito. Quer isto dizer que ela pretende libertar a ciência jurídica de todos os elementos que lhe são estranhos. Esse é o seu princípio metodológico fundamental. (...)

Quando a Teoria Pura empreende delimitar o conhecimento do Direito em face destas disciplinas, fá-lo não por ignorar ou, muito menos, por negar esta conexão, mas porque intenta evitar um sincretismo metodológico que obscurece a essência da ciência jurídica e dilui os limites que lhe são impostos pela natureza de seu objeto.(KELSEN, 1999, p.1-2)
\end{abstract}

Tais teorias, no entanto, já não são mais suficientes para se analisar a Ciência Jurídica, seus métodos e finalidades. A partir do estabelecimento da noção da complexidade das relações sociais, que não podem ser compreendidas em sua plenitude pelo mero aumento da eficiência dos procedimentos, surgiram novas condições de concepção das Ciências Sociais Aplicadas, dentre elas a do Direito.

A Ciência Jurídica contemporânea apela à razoabilidade, ao conhecimento crítico e à reconceituação do ato justo, sendo suas formas de produção de conhecimento discursivas e seu conjunto de complexos argumentativos voltados para a validade dos argumentos a partir de sua relevância prática e de sua capacidade de emancipação dos grupos sociais e indivíduos (SOUSA e DIAS, 2010, p. 11). Nas palavras das professoras Miracy Barbosa de Sousa e Maria Tereza Dias: "Só podem ser considerados emancipados aqueles grupos de pesquisadores que, a partir dos conhecimentos científicos, convencem-se da validade dos argumentos e do saber produzido e, por isso, adquirem a capacidade de julgá-los e justificá- los perante si mesmos e os demais" (SOUSA e DIAS, 2010, p. 11).

Conforme explica Marcos Nobre, na atualidade, faz-se necessário ampliar o conceito de dogmática e, portanto, o seu campo de aplicação de modo que os pontos de vista da sociologia, da história, da antropologia, da filosofia ou da ciência política não sejam exteriores, tampouco auxiliares, mas se incorporem à investigação dogmática como momentos constitutivos. 
Assim, repousa no conhecimento científico a capacidade de evolução dos pesquisadores, uma vez que é ele que viabiliza a autocrítica e verificação do trabalho produzido. Existe, no entanto, em nossas universidades uma perigosa simplificação dos significados atribuídos ao conhecimento científico e à pesquisa científica.

As faculdades e universidades são um reflexo do meio de ratificações que vige na sociedade, onde a criação individual é sempre objeto de julgamentos que levam em cona os critérios em vigor e, não raro, resistem às revoluções. Tal fato não pode ser negado, pelo que o trabalho acadêmico, desde aquele produzido em meio ao curso de Direito, visando somente a obtenção de pontos em uma disciplina, e chegando à esse de doutorado, pode e deve ser encarado como um rito de passagem, não muito adequado às revoluções e apropriado às demonstrações de domínio da tradição acadêmica, seja em sua forma, seja em seu conteúdo. (MAMEDE, 1966, p.25)

Não se está propondo aqui um completo abandono do que já foi produzido, no entanto, como afirma Gladston Mamede, "o respeito à tradição, no entanto, não pode traduzir mediocridade; não é servilismo, mas consideração.” (1966). O espaço para a renovação é vasto e deve ser preenchido uma vez que há sempre muito por corrigir, muito por redizer, muito por atualizar, devendo tais empreitadas serem realizadas a partir de uma metodologia, conforme se verá mais detalhadamente a seguir.

A definição mais simples de pesquisa poderia ser formulada, a partir das idéias propostas por Karl Popper, como a procura de respostas para problemas propostos que não encontram solução imediata suficiente na literatura já produzida até o momento. Afirma-se, pois, que uma pesquisa científica origina-se sempre de uma indagação sem solução imediata. Se essa resposta é passível de ser encontrada por meio de simples consulta a revistas, livros e outras fontes, sem que seja necessária a utilização de uma metodologia sistemática e verificável de investigação, tal trabalho deve ser considerado como simples aprofundamento de estudo sobre determinado tema, não podendo ser classificado como investigação científica.

Boaventura de Sousa Santos (2002) entende a teoria crítica como aquela que não reduz a realidade ao que existe, pois a mesma se constitui de campos de possibilidades que devem ser confirmadas ou superadas. As Ciências Sociais Aplicadas, de modo geral, se debruçam primordialmente sobre a natureza moral da sociedade, refletindo, inclusive sobre a qualidade dessa moral. Nessa linha, as investigações no campo do Direito deverão estar voltadas para a busca de possibilidades emancipatórias. 
Resta mais definido, portanto, o objeto de estudo da pesquisa jurídica, no entanto, conforme já abordado anteriormente, o conhecimento cientifico não é produzido de maneira orgânica, pela mera observação de fatos e cogitação de hipóteses. A metodologia da pesquisa é parte fundamental da produção de um trabalho que se pretenda, além de acadêmico, científico.

Um conhecimento que se pratica sem apuro técnico e orientação epistem ológica acaba se revelando frágil e insustentável. Em face desse quadro, é louvável a iniciativa de atrair os estudos metodológicos para a formação do ensino jurídico, ainda que a mera inserção de uma disciplina na grade curricular não seja suficiente à modificação da mentalidade de uma geração de juristas excessivamente acostumados a avaliações quantitativas e à valorização excessiva da prática.

A disciplina da pesquisa é o que se chama método; corresponderia a uma espécie de planejamento de recursos, técnicas e meios de se investigar determinado objeto de estudo. O método será o diferencial que haverá de conferir ao conhecimento produzido na área jurídica a sistematicidade necessária para a elaboração de uma pesquisa científica. Sobre a pouca familiaridade dos operadores do direito com os procedimentos científicos, é significativa a observação de Eduardo C. B. Bittar:

\begin{abstract}
Se são muitos os déficits da pesquisa jurídica no Brasil, sobretudo entendendose que escassa é a intimidade da grande massa de operadores do direito com os procedimentos científicos e com as reflexões metodológicas, há que se destacar que o maior déficit da pouca produção cientifico - jurídica brasileira, ou seja, aquele que mais acentuadamente marca a defasagem das pesquisas jurídicas em face das demais ciências, é o decorrente da ausência de pesquisas empíricas na cultura jurídica nacional, $[\ldots]$

Enfim, o saber jurídico que se constrói usualmente não chega a ser dentro de critérios metodológicos, ou, muito menos, por vezes, a produzir material de pesquisa adequado dentro de parâmetros de produção intelectual das ciências humanas, pois se vale exaustivamente e insistentemente de métodos dedutivonormativos para a construção do conhecimento jurídico (norma $\rightarrow$ caso, ou norma $\rightarrow$ dogma $\rightarrow$ ciência), que raramente extravasa a linha da exegese textual da lei.
\end{abstract}

As Ciências Sociais lidam com material fundamentalmente sociocultural e discursivo. Os métodos para lidar com esse arsenal de informações e fontes de estudo são os mais variados, podendo-se apontar o dialético, o sistemista, o estruturalista, o funcionalista ${ }^{2}$.

\footnotetext{
2 A proposta é de Demo: "Em ciências sociais, manipulamos geralmente uma gama de variada e historicamente contextualizada metodologia. Podemos destacar, entre outras, o empirismo, que imagina encontrar cientificidade no cuidado com a observação e com o trato da base experimental; o positivismo, que aparece em varias versões, desde sugestões do tipo de Comte, misturadas com religião, até aquela chamada de positivismo lógico, girando em torno das características lógicas do conhecimento ou do positivismo de Popper e Albert, muito crítico e influenciado pela discussão com a dialética e que vê na neutralidade cientifica uma opção possível entre ouras; o estruturalismo, que revive profundamente a crença ocidental cientifica da ordem interna das coisas e das invariantes explicativas; o funcionalismo, muito ligado a faces mais sociais da realidade e empenhado na explicação dos lados mais consensuais dela; o sistêmico, à sombra da moderna teoria dos sistemas, comprometido com a sobrevivência dos sistemas e com o manejo dos conflitos; a dialética, que se faz a expectativa de ser a metodologia especifica das ciências sociais, porque vê na historia não somente o fluxo das coisas, mas igualmente a principal origem explicativa” (DEMO. Introdução à metodologia da ciência,1987,p.21).
} 
A escolha de um método, no entanto, não mascara opções, escolhas, tendência e muito menos ideologias. Tal situação é incontornável para todas as ciências, sobretudo para aquelas intituladas sociais ou humanas. Ao menos, o método escora cientificamente uma posição assumida por aquele que se vale de um eixo de reflexão, podendo-se concordar ou discordar dele.

Vê-se, portanto, a relevância da metodologia na pesquisa científica. Quando se aborda a sistematicidade, a organização e a logicidade que caracterizam as pratica cientifica, isso também toca no âmbito jurídico. Assim, quando se afirma que a ciência é uma pratica social engajada, sobretudo o é a ciência jurídica, uma vez que lida diretamente com o fenômeno do poder instituído, das normas estatais, dos imperativos de conduta, etc.

Sobre a ciência jurídica, Eduardo C. B. Bittar escreveu:

\begin{abstract}
Deve-se dizer que a ciência jurídica é parte das ciências humanas por estar comprometida coma causa humana. Ao versar sobre os direitos, os deveres, os poderes, as faculdades, as instituições, as praticas burocráticas...está lidando diretamente com questões de interesse humano, quando não com os próprios valores humanos. Assim, estão em jogo a liberdade, a moralidade, o comportamento...todos esses valores de intensa significação humana.
\end{abstract}

Delineia-se, portanto, uma perspectiva de significado para a pesquisa jurídica que extrapola a mera compilação de dados ou a pura analise da norma. Deve o conhecimento cientifico, nesse rol incluso conhecimento jurídico, conforme visto acima, ir além do que já está posto, sendo nesse sentido essencial a crítica às constantes repetições de temas e enfoques, bem como o desprezo pela inovação.

\title{
3 O PAPEL DA INOVAÇÃO NA PESQUISA JURÍDICA
}

O debate sobre a pesquisa e o ensino jurídico no Brasil não é novo, sendo constantemente revisitado em incansáveis tentativas de nomear os problemas e definir soluções.

Marcos Nobre, professor de Filosofia da Unicamp e pesquisador do Cebrap, é categórico ao afirmar que a bem da verdade não existe pesquisa no âmbito jurídico e que "os cientistas sociais ainda costumam olhar com desconfiança a produção teórica em direito, já que aí não encontram os padrões científicos requeridos” (NOBRE, 2009, 
p.06). Indo além, complementa seu raciocínio no sentido de que os teóricos do direito alcançam uma posição de consultores e não de atores de investigações interdisciplinares.

$\mathrm{Na}$ prática, conforme entendimento de Alexandre Veronese e Roberto Fragale Filho, tal confusão se torna ainda mais aparente na medida em que parte das revistas jurídicas insistem em publicar acórdãos, sentenças e pareceres, como se fossem artigos (VERONESE e FRAGALE FILHO, 2015, p. 310).

Analisando detidamente, é possível concluir que um dos grandes problemas da pesquisa no âmbito jurídico é, de fato, a qualificação dos pesquisadores. $\mathrm{O}$ ensino jurídico no Brasil, ao menos no bacharelado, não está focado em pesquisa e reflexão acadêmica, o que reflete diretamente no desenvolvimento do raciocínio crítico.

De acordo com Maria Tereza Sadek é possível constatar:

\begin{abstract}
[...] que a maior parte das faculdade de direito instaladas no país são meras fábricas de bacharéis. São cursos baseados em aulas conferências, sem nenhum espaço quer para a pesquisa, quer para reflexões de maior envergadura. Mesmo nos cursos mais tradicionais e de melhor nível - normalmente vinculados a universidades públicas - não existem disciplinas voltadas para a pesquisa empírica (SADEK, 2002).
\end{abstract}

Observa-se que o problema dos pesquisadores vem desde a fase da graduação, na medida em que "nem sempre o discente tem consciência de que a monografia ou o documento final de projetos de pesquisa são relatórios de investigação. Ora, se o produto é um relatório de pesquisa, obviamente, é sempre necessária a realização de uma investigação que o anteceda" (FRATTARI, 2014).

A falta de qualificação dos pesquisadores gera a falta de inovação, fator preocupante nos tempos atuais. Essa falta de originalidade, na visão de Eduardo C. Silveira Marchi, acaba por comprometer a produção científica. De acordo com ele, "deve o autor, na medida do possível, dizer algo que ainda não foi dito, isto é, “descobrir" algo, ou, pelo menos, reconfirmar, com uma óptica diversa, o que já outrora se disse. ”(MARCHI, 2009, p. 21)

Nesse sentido, o critério para seleção de temas problemas deveria estar associado ao volume de estudos já realizados a respeito. Nas palavras de Eduardo C. Silveira Marchi: "em termos novos: um fenômeno tanto mais merece ser objeto de uma nova pesquisa quanto mais escassas ou, pelo menos, quanto mais inexpressivas forem as contribuições já existentes. ”.(MARCHI, 2009, p. 49)

No mesmo sentido, porém em outro enfoque, ao discorrer sobre as dissertações, trabalhos estes apresentados ao final do curso de pós-graduação stricto sensu, Orides 
Mezzaroba e Cláudia Servilha Monteiro, abordam a contribuição que o trabalho deve acrescentar ao debate:

[,,,] a dissertação deve mostrar sua contribuição para o debate sobre o tema objeto do seu trabalho. Esse tema pode não ser novo, mas a abordagem, com certeza, deverá ser inovadora, e mais, deverá apontar para perspectivas antes não tratadas, portanto inéditas. Então, está claro que na dissertação há certo compromisso com a originalidade, ainda que em menor grau, se comparada com a que se espera de um tese (MEZZOROBA e MONTEIRO, 2008, p.129).

Não só nos cursos de graduação de todo o país, mas, também, nos cursos de pósgraduação ofertados, o quesito inovação tem sido relativizado, ou até mesmo desconsiderado, na sua essência. Estamos habituados a fazer defesas de hipótese em vez de realizarmos verdadeiros testes de hipótese. Conquanto isso possa ser usado (e efetivamente seja usado) para reforçar uma suposta especificidade da pesquisa em direito que, ao cabo, só faz ampliar seu (nosso) isolamento -, essa postura se traduz por uma forte contaminação do trabalho acadêmico pela prática forense, ou seja, pela tradição da predominância da prática sobre a teoria. Em outras palavras, os trabalhos acadêmicos jurídicos estão essencialmente estruturados a partir do binômio problemasolução, em vez de enfrentarem a metodologia de hipótese-demonstração (VERONESE E FRAGALE FILHO, 2015).

Nas palavras de Alexandre Veronese e Roberto Fragale Filho, tal fato se acentua na postura adotada pelos pesquisadores, que não corresponde ao modelo acadêmico:

A leitura da produção efetuada no âmbito da pós-graduação em direito é, nesse sentido, bastante reveladora. Com raras exceções, dissertações e teses não possuem uma hipótese, mas partem de um problema e, após recensear as diferentes possibilidades de solução, indicam qual lhes parece ser a mais adequada das respostas. Pouca ou nenhuma demonstração é efetivamente realizada, o que explica, por um lado, a tíbia importância atribuída aos aspectos metodológicos dos trabalhos

e, por outro lado, a forte característica abntiana das correlatas disciplinas nos programas de pós-graduação em direito (VERONESE e FRAGALE FILHO, 2015, p. 328).

$\mathrm{Na}$ medida em que o escalonamento vertical do conhecimento tem sido cada vez mais procurado e difundido, torna-se ainda mais premente a discussão sobre a produção oriunda dos programas de pós-graduação, principalmente os stricto sensu. O aumento constante do número de alunos na pós-graduação trouxe a atividade de pesquisa para o centro das discussões sobre o ensino jurídico (FRATTARI, 2014). 
Atualmente, o discente de pós-graduação, lato sensu e stricto sensu, não é apenas aquele individuo que deseja aprofundar-se no estudo de uma área, enfrentando problemas teóricos e práticos da disciplina. É comum verificar que o principal interesse dos pósgraduandos e mestrandos, por exemplo, é a mera obtenção de um título que lhes proporcionará melhores condições salariais e um status diferenciado no mercado.

No entanto, o problema da ausência de inovação na pesquisa jurídica não possui como única causa o despreparo dos pesquisadores. Há que se considerar que outros fatores, tais como as exigências quantitativas crescentes, contribuem, em muito, para a criação do ambiente homogêneo que se verifica no campo da pesquisa jurídica no Brasil.

Os pensadores Pierre Weil, Jean-Ives Leloup e Roberto Crema chamaram adotam o termo "normose", definindo-o como a doença da normalidade. Algo bem comum no meio acadêmico de hoje. Para Weil, a normose pode ser definida como um conjunto de normas, conceitos, valores, estereótipos, hábitos de pensar ou de agir, que são aprovados por consenso ou por maioria em uma determinada coletividade e que provocam sofrimento, doença e morte. Crema afirma que um indivíduo normótico é aquele que se adapta a um contexto e a um sistema doente, e age como a maioria. E para Leloup, a normose é um sofrimento, a busca da conformidade que impede o encaminhamento do desejo no interior de cada um, interrompendo o fluxo evolutivo e gerando estagnação (SOUZA, 2014).

Estes conceitos, embora fundados sobre um propósito de análise pessoal e existencial, são muito pertinentes ao que se vive hoje na academia. Pela normose não é apenas o indivíduo que adoece, que estagna, que deixa de realizar o seu potencial criador, mas o próprio conhecimento. Em outras palavras, o problema da pesquisa jurídica desenvolvida atualmente no Brasil pode ser entendido a partir da concepção de um sistema de mera reprodução, com raras exceções que refletem aprofundado trabalho de pesquisa, que se retro alimenta e é favorecido, não somente pelo despreparo de seus operadores, mas pelas exigências constantes de seus avaliadores.

Renato Santos de Souza, em seu artigo sobre o fenômeno da normalidade nas universidades brasileiras, relata o testemunho de Peter Higgs, Prêmio Nobel de Física de 2013, que teria afirmado não encontrar lugar para si no meio acadêmico de hoje, pois não seria considerado suficientemente produtivo, e, em decorrência disso, provavelmente não teria descoberto o Bosão de Higgs (a "partícula de Deus") se tivesse de se dedicar à pesquisa atualmente. Higgs teria afirmado ainda ser considerado uma 
vergonha para o seu departamento, dada a sua baixa produção de artigos, reconhecendo que, nos dias de hoje, com a obsessão por publicações no ritmo do "publique ou pereça", não teria tempo nem espaço para desenvolver a sua teoria.

Sobre tais afirmações, Renato Santos de Souza se manifestou de maneira contundente e esclarecedora:

\begin{abstract}
A mim, embora não surpreendam, as declarações de Higgs soam estarrecedoras: ou seja, com os sistemas meritocráticos de avaliação de hoje, que privilegiam a produção de artigos e não de conhecimentos ou de pensamentos inovadores, uma das maiores descobertas da humanidade nas últimas décadas, que rendeu a Higgs o Nobel em 2013, provavelmente não teria ocorrido, como certamente muitos outros avanços científicos e intelectuais estão deixando de ocorrer em função dos sistemas atuais de avaliação da "produtividade em pesquisa". É a Normose acadêmica fazendo a sua maior vítima: o próprio conhecimento. (SOUZA, 2014)
\end{abstract}

O sistema que incentiva, avalia e premia a produtividade em pesquisa é, portanto, a principal causa do fenômeno da repetição na pesquisa jurídica. A atual situação da acadêmica se deve, em muito, à meritocracia produtivista implantada nas universidades, cujos instrumentos de manutenção são os sistemas de avaliação de pesquisadores e programas de pós-graduação, capitaneados principalmente pela CAPES e pelo Conselho Nacional de Desenvolvimento Científico e Tecnológico (CNPq).

As exigências trazidas por esses órgãos para qualificação dos programas de pósgraduação, bem como para a titulação dos discentes, deveriam ser voltadas para a garantia de um aproveitamento elevado dos futuros mestres no âmbito da pesquisa, já que, os mesmos, ao se submeterem a um curso stricto sensu, ao menos em teoria, se comprometem com a acadêmica e o desenvolvimento do pensamento jurídico.

Estes sistemas, no entanto, têm transformado, nas últimas décadas, docentes e alunos em burocráticos produtores de artigos, afastando-os dos reais problemas da ciência e da sociedade, bem como da busca por conhecimentos e pensamentos originais. A exigência de produtividade é um estímulo ao status quo, obstruindo a criatividade, a iniciativa, o senso crítico e a inovação, pois inovar pode ser arriscado quando se tem metas produtivas a cumprir. Inovar, não é, portanto, desejável. O mais seguro é fazer "mais do mesmo", abdicando-se, salvo raras exceções, do caráter de inovação inerente ao raciocínio cientifico (SOUZA, 2014). 
$\mathrm{Na}$ prática, conforme entendimentos acima expostos, as teses e dissertações no âmbito jurídico se apresentam cada vez mais baseadas em repetições, que nada acrescentam no campo da pesquisa acadêmica.

Ao se analisar as dissertações produzidas nas três maiores universidades do estado de Minas Gerais, a saber, Fundação Mineira de Educação e Cultura - FUMEC; Pontifícia Universidade Católica - PUC Minas; Universidade Federal de Minas Gerais - UFMG, a conclusão fundamental a que se chega é no sentido de estarem os trabalhos cada vez mais distantes do que aqui se conceitua como pesquisa jurídica de caráter cientifico, estando notoriamente ausente, na maioria dos casos, o caráter de inovação.

O levantamento apurado no estudo, relativo aos últimos três anos (2013-2015), esbarra na realidade de que as dissertações apresentadas são, na maioria, enquadradas no âmbito público, ficando a esfera privada restrita a discussões empresariais.

Ademais, após uma análise detalhada nos limites aqui delineados, verifica-se que a repetição de temas, tanto no que se refere aos títulos - como linhas condutoras dos trabalhos -, quanto aos tópicos abortados ao longo das dissertações se mostra consistente. Há quase invariavelmente a presença de capítulos que abordam digressões históricas que em nada acrescentam à discussão, bem como a revisitação, para suposta definição, de conceitos como Estado Democrático de Direito, Constituição, Análise Econômica do Direito, Processo, etc.

Mesmo quando os temas não são categoricamente repetitivos, a taxa de inovação é baixa, na medida em que assuntos como parceria público-privada, terceirização e análise econômica do direito, se mostram presentes ano após ano, nas três universidades aqui estudadas. E, ainda mais grave que a repetição de temáticas, é verificar que, em regra, não há inovação na abordagem ou preocupação com o que o trabalho poderá acrescentar ao debate jurídico, estando presente quase que na totalidade dos trabalhos capítulos inteiros que podem ser definidos, nas palavra de Miracy Barbosa de Sousa e Maria Tereza Dias, "como um estudo mais ou menos aprofundado sobre determinado tema que não deve ser visto como uma investigação cientifica” (2010).

Tal realidade se mostra distante do panorama traçado pelo Parecer $n^{\circ}$ 977/65, C.E,Su, aprovado em 03/12/1965, que determina como características fundamentais da pós-graduação stricto sensu a natureza acadêmica e de pesquisa, sendo certo que mesmo quando voltada para setores profissionais deve ter objetivo essencialmente cientifico.

O leque de possibilidades que permeiam o universo jurídico é amplo e instigante, razão pela qual não se justifica o comodismo aqui evidenciado. Porém, para se reverter 
esse cenário faz-se necessário repensar o modo como se produz e se avalia a produção acadêmica no âmbito jurídico. Apenas para exemplificar, na última década, os investimentos do CNPq nas áreas de Economia e Administração representaram, em cada uma, cerca de três vezes mais do que foi destinado ao Direito (OLIVEIRA, 2016). No mesmo sentido, porém com implicações ainda mais gravosas, identificamos recursos alocados pelo CNPq para as áreas de sociologia, antropologia, ciência política e economia, com a finalidade fomento a pesquisas de cunho jurídico.

\footnotetext{
Ou seja, essas áreas externas ao direito possuíam mais recursos para estudar o direito do que os juristas. (...) É evidente, assim, que as metodologias de pesquisa quantitativa, qualitativa e comparativa começaram a ser inicialmente utilizadas por cientistas sociais que se dedicaram a estudar o direito e isto originou certa rejeição pela área de direito a tais metodologias ( VERONESE e FRAGALI FILHO, 2015, p.320 -321).
}

A noção de pesquisa acadêmica no âmbito jurídico, em suas mais variadas frentes, precisa ser repensada com urgência no Brasil, sob pena de converter-se a ciência jurídica em mera prática calcada em sistemas de reprodução irrefletida.

\section{CONCLUSÃO}

O tema da pesquisa científica no âmbito jurídico vem sendo debatido ao longo de anos, no entanto ainda se verifica uma significativa redução dos significados e implicações atribuídos a essa. Comumente, acepções de pesquisa extraídas do senso comum são adotadas para definir o conhecimento cientifico, o que prejudica a evolução do pensamento jurídico, criando uma cortina de fumaça de produção técnica. $\mathrm{O}$ fato é que nem tudo que se produz no âmbito acadêmico pode, verdadeiramente, ser considerado pesquisa de caráter cientifico.

Isso não significa que bons estudos, incluindo a síntese da opinião de diversos autores, por exemplo, não possuam nenhum valor ou não sejam necessários ao desenvolvimento das pesquisas científicas. Mas não se pode confundir aprofundamento de estudos ou revisão bibliográfica com pesquisa científica.

Em face de toda a discussão suscitada no presente trabalho, que não pretende esgotar a questão, mas fomentar o debate, pode-se concluir que uma pesquisa científica aplicada ao campo jurídico do conhecimento possui concepção muito mais complexa do que comumente se-lhe atribui. Tal complexidade torna-se ainda mais evidente em face do 
objeto de estudo do Direito que, diferentemente do proposto por Kelsen, não são simplesmente as normas, mas todo um contexto social no qual essas se inserem.

Resta evidente, portanto, o potencial transformador da ciência jurídica, se a essa for permitido o tempo necessário de maturação e a submissão a processos metodológicos que lhe conferiram respaldo. Verifica-se, no entanto, que está instalada uma cultura de reprodução e repetição irrefletida no âmbito da produção acadêmica em Direito, não havendo, em regra, preocupação com a inovação e a contribuição que o trabalho poderia oferecer ao debate de questões polêmicas.

Conforme analisado acima, contribuem para esse cenário de homogeneidade tanto o sistema de ensino, que não forma pesquisadores, mas treina os discentes para a pratica forense, quanto as exigências formais de órgão como a CAPES e o CNPq.

Em síntese, em uma sociedade em que as instituições de ensino de direito não produzem o que transmitem, e o que se transmite não reflete o conhecimento produzido, sendo os sistemas de avaliação dessas, de seus docentes e discente fundado em sistemas quantitativos, a pesquisa jurídica de caráter científico está, no mínimo, comprometida.

\section{REFERÊNCIAS BIBLIOGRAFICAS}

CAPES. ORIENTAÇÕES PARA APCN - 2016. Disponível em: http://www.capes.gov.br/images/documentos/Criterios_apcn_2016/Criterios_APCN_Direit o.p df. Acesso em: 08 de abril de 2016.

CAPES. Parecer no 977/65, C.E,Su, aprovado em 03/12/1965, p. 04. Disponível em: https://www.capes.gov.br/images/stories/download/legislacao/Parecer_CESU_977_1965.do c. Acesso em 27 mar. 2016.

BITTAR, Eduardo C. B..Metodologia da pesquisa jurídica: teoria e prática da monografia para os cursos de direito. 11 ed. São Paulo: Saraiva, 2013.

FRATTARI, Rafhael. O conceito de ciência em Hans Kelsen. Belo Horizonte. Acervo pessoal, 2002.

FRATTARI, Rafhael. O projeto de pesquisa e a iniciação científica em Direito. Belo Horizonte: Meritum, 2014, v. 9, n. 1.

GUSTIN, Miracy Barbosa de Sousa; DIAS, Maria Tereza Fonseca. (Re)Pensando a Pesquisa Jurídica. 3 ed. Belo Horizonte: Del Rey, 2010.

KELSEN, Hans. Teoria Pura do Direito. 6 ${ }^{\text {a }}$ ed. São Paulo: Martins Fontes, 1999 (Orig. Reine Rechtslehre; trad. João Baptista Machado). 
KESSELRING, Ana Beatriz; SALES, Rodrigo; OLIVEIRA FILHO, Vicente. Pesquisa jurídica: uma ferramenta essencial aos operadores do Direito. Consultório Jurídico:

27/09/2015. Disponível em: http://www.conjur.com.br/2015-set-27/pesquisajuridica-ferramenta-essencial-aos-operadores-direito. Acesso em: 28 de mar. 2016.

MARCHI, Eduardo C. Silveira. Guia de Metodologia Jurídica - 2. ed. São Paulo: Saraiva, 2009.

MEZZOROBA, Orides, MONTEIRO, Cláudia Servilha. Manual de Metodologia da Pesquisa no Direito, 4. Ed. São Paulo: Saraiva, 2008.

NOBRE, Marcos. Apontamentos sobre a Pesquisa em Direito no Brasil. Cadernos Direito GV, p. 06.

OLIVEIRA, Luciano; ADEODATO, João Maurício. O estado da arte da pesquisa jurídica e sócio-jurídica no Brasil. Disponível em:

http://daleth.cjf.jus.br/revista/seriepesq04.htm. Acesso em 25 mar. 2016.

OLIVEIRA, Paulo Eduardo de (org.). Ensaios sobre o pensamento de Karl Popper. Curitiba: Circulo de Estudos Bandeirantes, 2012.

SADEK, Maria Tereza. Estudos sobre o sistema de justiça. In MICELI, Sérgio (Org.). O que ler na ciência social brasileira (volume IV). São Paulo: Sumaré e ANPOCS, 2002.

SANTOS, Boaventura de Sousa. A crítica da razão indolente: contra o desperdício da experiência. Para um novo senso comum: a ciência, o direito e a política na transição paradigmática. 4 ed. São Paulo: Cortez, 2002.

SOUZA, Renato Santos de. A doença da "normalidade" na universidade. In NASCIMENTO, L.F.M. (Org.) Lia, mas não escrevia (livro eletrônico): contos, crônicas e poesias. Porto Alegre: LFM do Nascimento, 2014.

VERONESE, Alexandre; FRAGALE FILHO, Roberto. Ensinar direito o Direito. São Paulo: Saraiva, 2015. 